\title{
Treatment Failure of Active Vitamin D Therapy in Chronic Kidney Disease: Predictive Factors
}

\author{
Mario Cozzolino ${ }^{a}$ Adrian Covic $^{\mathrm{b}}$ Blanca Martinez-Placencia ${ }^{\mathrm{c}}$ \\ Konstantinos Xynos ${ }^{c}$ \\ aDepartment of Health Sciences, University of Milan, Milan, Italy; ' University of Medicine and Pharmacy 'Gr. T. Popa', \\ Iasi, Romania; ' $A$ AbbVie Inc., North Chicago, III., USA
}

\section{Key Words}

Vitamin D failure · Secondary hyperparathyroidism .

Chronic kidney disease

\begin{abstract}
Background: In patients with chronic kidney disease (CKD), impaired renal function leads to decreased vitamin D levels, which causes an increase in parathyroid hormone (PTH) production and contributes to the development of secondary hyperparathyroidism (SHPT). This may result in adverse clinical effects such as bone disorders, vascular calcification, cardiovascular disease, and increased mortality. Current treatment practices and associated outcomes with active vitamin $D$ treatment in patients with CKD were reviewed with the objective to assess parameters (such as PTH and serum calcium levels) that may be used to define the failure of vitamin D treatment. Summary: Reports based on observational data have noted improved outcomes with active vitamin D treatment (calcitriol, paricalcitol, alfacalcidol, or doxercalciferol) in patients with CKD. Criteria for the identification of active vitamin $D$ treatment failure are unclear from current guidelines, although up to $50 \%$ of patients may experience treatment failure eventually because of development of hypercalcemia or resistant SHPT, characterized by an elevated intact PTH (iPTH) level despite treatment. We propose a def-
\end{abstract}

inition of vitamin D treatment failure as $\mathrm{PPTH}>600 \mathrm{pg} / \mathrm{ml}$ after 6 months of intravenous active vitamin $D$ treatment and corrected total calcium serum levels $>10.2 \mathrm{mg} / \mathrm{dl}$, and review factors that may predict the response to vitamin $D$ treatment. Key Message: Active vitamin D treatment failure is an important challenge in clinical practice. The aim of the proposed definition is to suggest a possible framework for hypothesis generation and to encourage further research into this common problem.

(c) 2015 S. Karger AG, Basel

\section{Introduction}

An estimated $10 \%$ of the US population has chronic kidney disease $(\mathrm{CKD})$, which occurs most often as the consequence of other chronic illness, especially hypertension and diabetes [1]. Worldwide, the prevalence is thought to be between 8 and $16 \%$ of the population, although it is challenging to determine the actual number of individuals affected [2]. CKD is progressive, with the disease classified in stages by the presence of kidney injury or impaired glomerular filtration rate (GFR; measured in $\mathrm{ml} / \mathrm{min} / 1.73 \mathrm{~m}^{2}$ ).

Secondary hyperparathyroidism (SHPT), manifested by increased production of parathyroid hormone (PTH)

\section{KARGER 125}

(C) 2015 S. Karger AG, Base

0250-8095/15/0423-0228\$39.50/0

E-Mail karger@karger.com

www.karger.com/ajn
Mario Cozzolino, MD, PhD, FERA

Department of Health Sciences

University of Milan

Via A. di Rudin, 8, IT-20142 Milan (Italy)

E-Mail mario.cozzolino@unimi.it 
associated with parathyroid hyperplasia, is a common and serious consequence of declining kidney function $[3,4]$. An analysis from the Study for the Evaluation of Early Kidney disease (SEEK) noted that the prevalence of SHPT (intact PTH $[\mathrm{iPTH}]>65 \mathrm{pg} / \mathrm{ml}$ ) begins to increase during stage 3 kidney disease, when the GFR falls below $45 \mathrm{ml} / \mathrm{min} / 1.73 \mathrm{~m}^{2}$, and increases across the spectrum of GFR reduction to include almost all patients with GFR $<20 \mathrm{ml} / \mathrm{min} / 1.73 \mathrm{~m}^{2}$ (fig. 1) [5].

SHPT results from a complex, multifactorial series of disturbances in mineral and bone metabolism, systems which normally exist in a finely tuned equilibrium [6]. The clinical implications of this disrupted balance may include renal osteodystrophy (bone loss, fragility fracture, bone deformity), vascular calcification $[7,8]$, cardiovascular disease [9], and increased mortality $[4,10]$.

A low level of vitamin D is among the key factors that may contribute to the development of SHPT, and vitamin $\mathrm{D}$ replacement is an important aspect of the treatment and prevention of SHPT [4]. The objective of this review is to describe the role of vitamin $\mathrm{D}$ replacement therapy in patients with advanced CKD, with a focus on identifying those patients most likely to experience active vitamin $\mathrm{D}$ treatment failure. We also propose a definition of vitamin D treatment failure as $\mathrm{iPTH}>600 \mathrm{pg} / \mathrm{ml}$ after 6 months of intravenous (IV) active vitamin D treatment and corrected total calcium serum levels $>10.2 \mathrm{mg} / \mathrm{dl}$.

\section{Pathophysiology of SHPT}

Under conditions of homeostasis, one of the key roles of the active form of vitamin D, 1,25-dihydroxyvitamin $\mathrm{D}_{3}\left(1,25(\mathrm{OH})_{2} \mathrm{D}_{3}\right)$, is suppression of serum levels of PTH and parathyroid hyperplasia via parathyroid vitamin D receptors $[4,10]$. With declining kidney function, $1,25(\mathrm{OH})_{2} \mathrm{D}_{3}$ levels decrease because of the reduced availability of $1 \alpha$-hydroxylase, an enzyme found mainly in the kidney, which is required for the final step in the synthesis of active vitamin D from exogenous sources [11]. Levels of vitamin D decline early in CKD, suggesting that this event is important for the development of SHPT. In SEEK, $1,25(\mathrm{OH})_{2} \mathrm{D}_{3}$ levels were correlated with GFR and were deficient (defined in the study as $<22 \mathrm{pg} / \mathrm{ml}$ ) when GFR was approximately $45 \mathrm{ml} / \mathrm{min} /$ $1.73 \mathrm{~m}^{2}$; this is the same level at which the prevalence of SHPT was observed to increase [5]. Another role of $1,25(\mathrm{OH})_{2} \mathrm{D}_{3}$ that is relevant to the development of SHPT is its stimulation of calcium absorption in the intestine. When the level of $1,25(\mathrm{OH})_{2} \mathrm{D}_{3}$ is low, intestinal

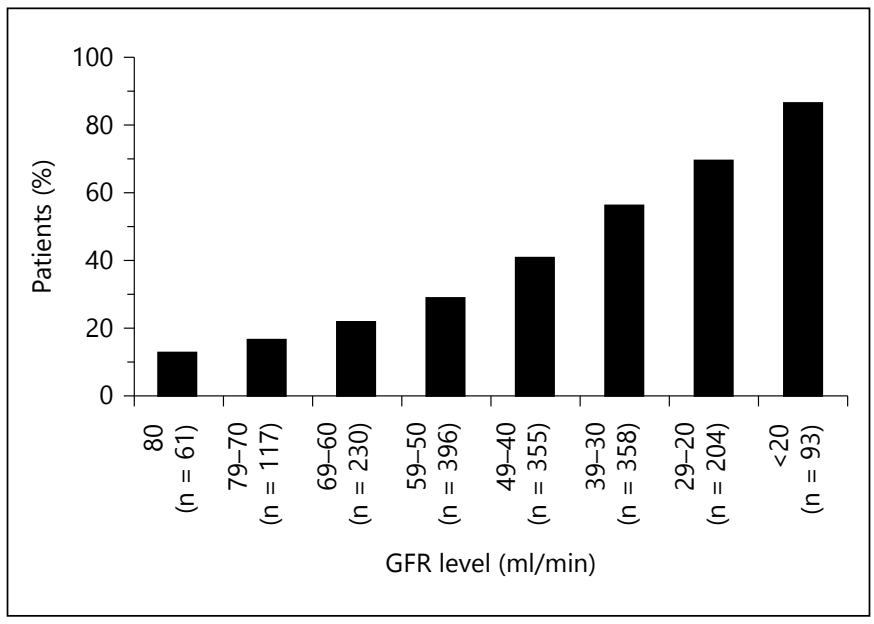

Fig. 1. Prevalence of SHPT (assessed by iPTH) in patients with CKD increases as the GFR declines [5].

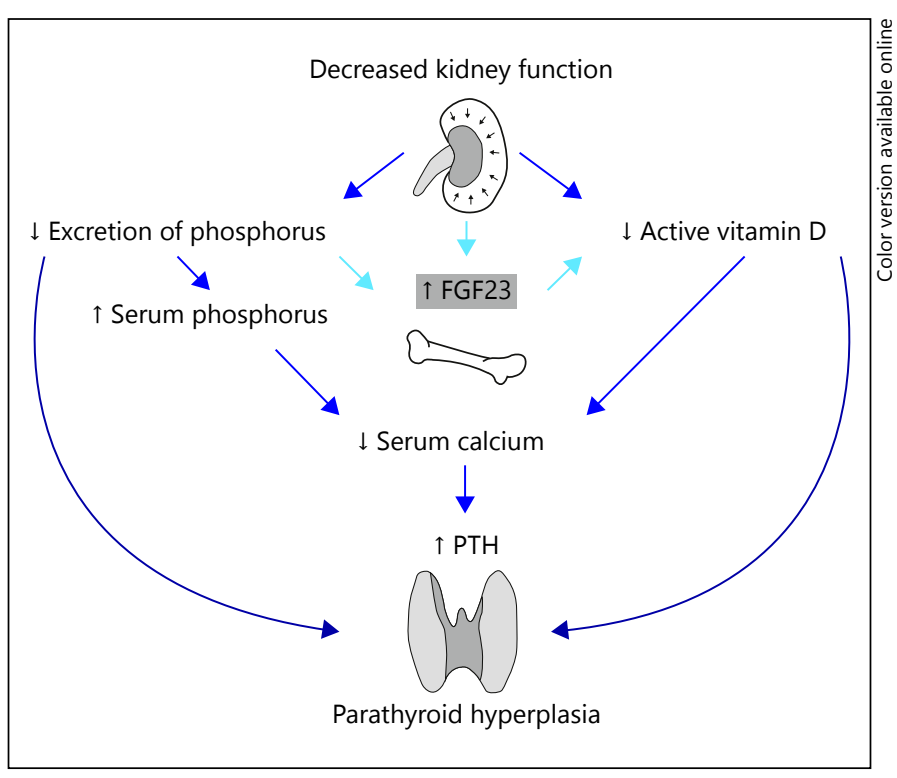

Fig. 2. Pathogenesis of SHPT $[14,15]$.

absorption of calcium decreases, contributing to a hypocalcemic state [12].

A progressive decline in kidney function also results in high plasma levels of phosphorus. Hyperphosphatemia promotes $\mathrm{PTH}$ production directly, and together with decreased $1,25(\mathrm{OH})_{2} \mathrm{D}_{3}$-mediated calcium absorption, result in hypocalcemia. Hypocalcemia, in turn, also stimulates PTH production and secretion (fig. 2) [13]. Fibroblast growth factor 23 (FGF23), a peptide produced by osteocytes, further contributes to the pathophysiology of SHPT. FGF23 levels have been shown to increase as renal 
function deteriorates. It is theorized that the rise in FGF23 levels reflects a homeostatic response to reduced phosphate excretion, which occurs as renal mass declines. FGF23 inhibits 1a-hydroxylase, thereby suppressing $1,25(\mathrm{OH})_{2} \mathrm{D}_{3}$. In addition, PTH itself appears to further stimulate FGF23 production $[14,15]$. Ultimately, in the setting of declining GFR, a cascade of adaptive changes within a tightly regulated system leads to highly disordered mineral metabolism, with salient features including decreased $1,25(\mathrm{OH})_{2} \mathrm{D}_{3}$ levels, hyperphosphatemia, hypocalcemia, and increased FGF23 and SHPT, with associated bone disease, vascular calcification, cardiovascular disease, and increased morbidity and mortality.

It should be noted that knowledge of this complex, multifactorial process is still evolving. Decreased expression of vitamin $\mathrm{D}$ and calcium-sensing receptors, as well as FGFR-Klotho have also been associated with parathyroid hyperplasia [16-19], and it is likely that other mediators (e.g. sclerostin $[20,21]$ ) also play a role in the deterioration of bone and vascular health in patients with CKD. However, a full discussion of these factors is beyond the scope of this review.

\section{Vitamin D Replacement Therapy in CKD}

Correction of low levels of vitamin D (deficiency or insufficiency, defined as 25-hydroxy-vitamin D levels $<30$ and $<15 \mathrm{ng} / \mathrm{ml}$, respectively) with vitamin D replacement therapy is one of the cornerstones of treatment for patients with CKD. Guidelines suggest that patients who have PTH levels that are rising persistently and are consistently above the upper limit of normal may receive treatment with active vitamin D or analogs (calcitriol, paricalcitol, alfacalcidol, or doxercalciferol) as part of an effort to prevent or slow the progression of SHPT [10]. Unfortunately, there are limited reports of well-designed, randomized, controlled studies of these agents, or for comparisons of the efficacy of active vitamin $\mathrm{D}$ or analogs, conducted in patients with CKD [10]. In one recently published (2014) trial in patients with CKD who were not undergoing dialysis, calcifediol for 6 weeks has been shown to significantly increase serum 25 -hydroxyvitamin D and decrease plasma iPTH ( $\geq 30 \%$ in $>60 \%$ patients treated with 60 or $90 \mu \mathrm{g} /$ day) levels compared with placebo [22]. In pre-dialysis patients with CKD stage 3 or 4, treatment with cholecalciferol for 12 weeks has been shown to significantly increase serum vitamin D compared with placebo; however, effects on plasma PTH levels were not statistically significant $(-31$ vs. $-7 \%$ for pla- cebo) [23]. In a single-blinded (to investigators), randomized 3-month trial of high-dose cholecalciferol vs. doxercalciferol, vitamin D levels were significantly increased from baseline in the cholecalciferol group, but not in the doxercalciferol group; the between-group difference was also significant [24]. The differences between the treatment groups for changes in iPTH levels were not significant, although in the doxercalciferol group, the decrease from baseline was significant $(-27 \% ; p=0.002)$. A prospective nonrandomized, observational study of ergocalciferol in patients with stage 3 or 4 CKD (mean duration, approximately 7 months) found that PTH level reductions were associated with kidney function, with significant decreases in PTH levels noted in patients with stage $3 \mathrm{CKD}(-13.1 \%, \mathrm{p}=0.041)$, but no statistically significant effects on PTH levels were found in patients with stage 4 CKD [25]. It should be noted that in many of these studies, outcomes are typically characterized by changes in biochemical measures (e.g. PTH, calcium, phosphorus, and markers of bone turnover) [26, 27], rather than those that may be most relevant to patients, such as quality of life, fracture incidence, cardiovascular events, or death [10].

\section{Relationships between Active Vitamin D Treatment and Mortality}

Evidence for the effects of active vitamin D treatment on hard clinical outcomes, such as mortality, has generally come from observational studies. Although such data provide associational support rather than definitive evidence, they suggest that active vitamin $\mathrm{D}$ treatment may improve survival in patients with CKD. Several retrospective studies have evaluated active vitamin $\mathrm{D}$ therapy in patients with stage $5 \mathrm{CKD}$ undergoing hemodialysis (HD) and identified an association between decreased mortality in patients who received vitamin $\mathrm{D}$ therapy compared with those who did not $[28,29]$. Other retrospective studies of patients with stages 3 to 5 CKD not yet on dialysis identified lower risks for mortality and for initiation of dialysis in patients treated with calcitriol, compared with untreated patients, suggesting the apparent benefit of active vitamin $\mathrm{D}$ treatment in this patient population as well $[30,31]$. Prospective, controlled studies are needed to confirm the apparent benefits of calcitriol treatment observed in these retrospective analyses.

A recent meta-analysis evaluating the effect of active vitamin D treatment found a significantly lower (27\%) all-cause mortality risk, and that the reduction in risk ap- 
Table 1. Recommendations for SHPT testing and treatment targets in KDOQI [4] and KDIGO [10] guidelines

\begin{tabular}{ll}
\hline KDOQI & KDIGO \\
\hline $\begin{array}{l}\text { PTH target ranges, pg/ml } \\
\text { CKD stage } 3,35-70\end{array}$ & $\begin{array}{l}\text { CKD stages 3-5: in patients not undergoing dialysis with PTH levels } \\
\text { above the URL, evaluate for hyperphosphatemia, hypocalcemia, and } \\
\text { CKD stage } 4,70-110\end{array}$ \\
vitamin D deficiency \\
In CKD stage 5D, consider maintenance of PTH levels within $\sim 2-9 \times$ \\
the URL of the assay \\
$\begin{array}{l}\text { Marked PTH changes within this range require treatment initiation or } \\
\text { modification }\end{array}$
\end{tabular}

$5 \mathrm{D}=$ Stage 5 on dialysis; $\mathrm{URL}=$ upper reference limit.

peared to be greater with longer follow-up. A reduction of $37 \%$ was observed in the relative risk of cardiovascular mortality. Further, a survival advantage was demonstrated in patients in the early stages of CKD, as well as in patients with CKD undergoing HD [32].

Prospective observational data from the Italian FARO survey [9] suggested that patients who received treatment for SHPT (calcitriol, paricalcitol, or cinacalcet with/without active vitamin D treatment) had reduced overall and cardiovascular-related risk of mortality versus untreated patients $(\mathrm{p}<0.001)$. Interestingly, a more recent analysis of the FARO study showed that active vitamin D treatment was associated with decreased all-cause mortality, even among patients with low iPTH levels $(\leq 150 \mathrm{pg} / \mathrm{ml}$; $\mathrm{p}<0.01$ ), who do not typically receive active vitamin $\mathrm{D}$ therapy in an attempt to avoid adynamic bone disease [33]. Again, controlled studies are necessary to determine if patients with low iPTH levels might indeed gain benefit from active vitamin D treatment.

\section{Guidelines for Treatment of Patients with Abnormal PTH Levels}

Two principal guidelines have been published on the prevention and management of disturbances in mineral and bone metabolism in patients with CKD. The first, published in 2003, was from the National Kidney Foundation Kidney Disease Outcomes Quality Initiative (KDOQI) [4]. These guidelines provide a US perspective and are based on expert evaluation of clinical evidence from a range of study types, including randomized, matched controlled, prospective, retrospective, and uncontrolled cross-sectional studies [4]. The second set of guidelines was developed by KDIGO (Kidney Disease: Improving Global Outcomes) in 2009. These guidelines provide a global perspective and were based only on randomized, controlled studies of at least 6 months' duration and with sample sizes of 50 or more patients [10]. The KDIGO guidelines have subsequently been endorsed by European Renal Best Practice and form the basis of care in countries across the globe $[34,35]$.

A commentary from a KDOQI working group on the KDIGO guidelines puts them in the context of US-delivered care and summarizes important differences between the 2 guidelines. Notably, the KDOQI expert group suggests that the KDIGO guidance, because it is based on more recent evidence, should supplant the 2003 KDOQI guidelines [36]. However, because the KDIGO guidelines included only randomized studies, definitive recommendations could not be made for widely and currently used treatment. Therefore, the KDOQI guidelines advocate flexibility in developing treatment goals and for weighing the benefits and risks of the approaches used in individual patients. Guidelines pertinent to the treatment of patients with SHPT, with relevant commentary from the KDOQI working group, are included in table 1 $[4,10]$.

\section{Active Vitamin D Treatment Failure: Definition}

Active vitamin D treatment is not effective in all patients. A primary cause of treatment discontinuation is hypercalcemia, which is observed in approximately 20 to $30 \%$ of patients whether they have end-stage renal disease and are undergoing HD [37], or have CKD and are not undergoing $\mathrm{HD}$ [38]. Concern for hypercalcemia is greater with 2 standard treatments for SHPT, calcitriol and alfacalcidol, which are non-selective activators of VDRs in other calcium-regulating organs, such as intestine and bone $[39,40]$. Preclinical studies provided robust evi- 
dence that these 2 agents have greater potential than other similar agents to induce hypercalcemia $[39,40]$; however, evidence for this effect has been difficult to determine in humans. A randomized study in patients with SHPT who were undergoing HD found that alfacalcidol and paricalcitol were equally effective in lowering PTH levels, and no differences between the agents were observed with regard to hypercalcemia [41]. A recent randomized trial in patients with stages 3 to 4 CKD found that the incidence of hypercalcemia was low and was similar with calcitriol and paricalcitol. Both agents were effective in lowering PTH levels, although a higher percentage of patients achieved PTH reduction $\geq 40 \%$ or PTH suppression $>60 \%$, as calculated versus baseline, when treated with paricalcitol as compared with calcitriol. A $40 \%$ reduction from baseline in PTH was also achieved more rapidly in patients who received paricalcitol than in those who received calcitriol [42]. Another prospective randomized trial, conducted in a small population of patients undergoing continuous ambulatory peritoneal dialysis $(n=26)$, found that the incidence of hypercalcemia was similar with paricalcitol (33\%) or calcitriol (29\%) treatment; likewise, suppression of iPTH by $\geq 50 \%$ from baseline was achieved by similar percentages of patients in either treatment group [43]. Whether one agent is superior to another remains to be determined in large controlled studies. A second cause of treatment failure (observed in approximately 20 to $30 \%$ of patients) is treatment resistance, whereby active vitamin $\mathrm{D}$ treatment becomes less effective over time in inhibiting parathyroid cell proliferation and $\mathrm{PTH}$ production, despite increasing doses [44]. Altogether, it may be expected that active vitamin $\mathrm{D}$ treatment will fail in 40 to $50 \%$ of patients.

Although hypercalcemia and resistant or refractory SHPT are recognized issues [4], they are not defined in published guidelines as a single concept that could serve to generate a hypothesis for clinical research and, eventually, to guide clinical practice. The KDOQI guidelines define hypercalcemia as serum levels of corrected total calcium $>10.2 \mathrm{mg} / \mathrm{dl}$ [4]. In the literature, hypercalcemia has been variously defined, ranging from serum calcium levels $>10$ to $>11.5 \mathrm{mg} / \mathrm{dl}$ [10]. In the context of active vitamin D treatment, the KDOQI guidelines suggest that treatment should be withheld when serum levels of corrected total calcium are $>10.2 \mathrm{mg} / \mathrm{dl}$ [4].

Similarly, various definitions of treatment resistance have been used, primarily in studies examining the efficacy of IV paricalcitol in patients with SHPT resistant to IV calcitriol. Llach and Yudd [45], for instance, defined treatment resistance as iPTH values $>600 \mathrm{pg} / \mathrm{ml}$ despite 6 months of treatment with IV calcitriol. Tonbul et al. [46] described treatment resistance as elevated serum iPTH $(>300 \mathrm{pg} / \mathrm{ml})$ despite treatment with calcitriol at a dosage of up to $9 \mu \mathrm{g} /$ week for 6 months. In a study by Vulpio et al. [47], this phenomenon was defined as iPTH $>300 \mathrm{pg} / \mathrm{ml}$ after patients received IV calcitriol therapy for at least 6 months. Kazama et al. [48] defined it as iPTH $300 \mathrm{pg} / \mathrm{ml}$ despite treatment with doses of up to $4.5 \mu \mathrm{g}$ of IV calcitriol per week for 24 weeks, whereas Capuano et al. [49] described treatment resistance as patients with $\mathrm{iPTH}>300 \mathrm{pg} / \mathrm{ml}$ who had received pulse IV calcitriol for at least 1 year.

On the basis of the varying definitions, and to advance the recognition of this important clinical problem, we propose a unifying definition for active vitamin $\mathrm{D}$ treatment failure in patients with stage $5 \mathrm{CKD}$ on dialysis that encompasses the concepts of hypercalcemia and resistance: iPTH $>600 \mathrm{pg} / \mathrm{ml}$ after 6 months of active IV vitamin D treatment (e.g. calcitriol) and serum calcium levels $>10.2 \mathrm{mg} / \mathrm{dl}$. Selection of these cut-off values for iPTH and calcium is based on expert opinion and should be confirmed by studies. Strong data are lacking that a lower iPTH cut-off value (i.e. $>300 \mathrm{pg} / \mathrm{ml}$ ) would be preferred, particularly because of the known high incidence of adynamic bone disease in patients undergoing HD, even when iPTH values are approximately $400 \mathrm{pg} / \mathrm{ml}$ or greater. Further, there have been no trials supporting a cut-off value for serum calcium levels $>9.5 \mathrm{mg} / \mathrm{dl}$, and the upper limit of the normal range for serum calcium is $10.2 \mathrm{mg} / \mathrm{dl}$ [4]. The values in the proposed definition of active vitamin $\mathrm{D}$ failure are meant to only to generate a hypothesis, and the definition can be refined as clinical data become available.

\section{Vitamin D Treatment Failure: Associated Features}

Several clinical features may be associated with vitamin D treatment failure. Identification of these characteristics in conjunction with individual laboratory parameters for serum calcium, phosphorus, and PTH may help predict poor patient response to active vitamin $\mathrm{D}$ treatment. In a 12-month prospective, open-label study, the number and size of the parathyroid glands of patients with a subclinical response to calcitriol were assessed before patients were switched to paricalcitol treatment [47]. A higher rate of treatment response (defined as iPTH $<300 \mathrm{pg} / \mathrm{ml})$ was observed at $6(23.5 \%)$ and 12 months $(41.2 \%)$ in patients with a smaller gland size (maximum 
longitudinal diameter $[\mathrm{MLD}] \leq 9 \mathrm{~mm}$ ) compared with responses at 6 and 12 months (7\% at both time points) in patients with larger gland sizes (MLD $>9 \mathrm{~mm}$ ) [47]. This study suggests that a larger parathyroid gland size may predict a poor response to active vitamin $\mathrm{D}$ treatment. Another study has indicated that pre-treatment PTH levels were predictive of outcomes of calcitriol therapy; patients with lower baseline PTH values were more likely to achieve a response than patients with higher baseline PTH values [50].

Another potential predictor of response to vitamin D treatment is FGF23 serum level. Elevated levels of FGF23 are detected in patients with SHPT, and FGF23 is part of a feedback loop that involves the upregulation of FGF23 and resultant downregulation of 1a-hydroxylase, which results in reduced vitamin D production [12]. Kazama et al. [48] conducted a study in which patients with iPTH levels $>300 \mathrm{pg} / \mathrm{ml}$ despite treatment with IV calcitriol underwent a 4 -week washout period and subsequent retreatment with calcitriol for 24 weeks $(n=66)$. The overall rate of treatment success (defined as iPTH $<300 \mathrm{pg} / \mathrm{ml}$ ) was $41.9 \%$. Patients with low iPTH $(\leq 591 \mathrm{pg} / \mathrm{ml})$ and FGF23 ( $\leq 9,860 \mathrm{ng} / \mathrm{l})$ levels at the re-initiation of calcitriol had a treatment success rate of $88.2 \%$. In contrast, only $4.2 \%$ of patients with high iPTH $(>591 \mathrm{pg} / \mathrm{ml})$ and FGF23 $(>9,860 \mathrm{ng} / \mathrm{l})$ at calcitriol re-initiation responded to treatment [48]. Therefore, FGF23 levels may be a useful predictor of response to active vitamin $\mathrm{D}$ treatment.

\section{Vitamin D Treatment Failure: Suggested Approaches to Changing Therapy}

In patients with CKD, few studies have been conducted on active vitamin $\mathrm{D}$ treatment that results in failure. Existing evidence is primarily from studies in which patients who have not been successfully treated with one agent (mainly calcitriol) have been switched to another agent (paricalcitol).

In a 12-month study assessing treatment with paricalcitol in patients intolerant or resistant to calcitriol ( $\mathrm{n}=$ 43), paricalcitol significantly reduced serum iPTH levels from $748 \mathrm{pg} / \mathrm{ml}$ at pre-treatment to $307 \mathrm{pg} / \mathrm{ml}$ at 12 months $(\mathrm{p}<0.001)$ [46]. Levels of calcium, phosphorus, and calcium $\times$ phosphorus product did not change significantly over the 12-month assessment period [46]. Capuano et al. [49] evaluated treatment with paricalcitol in 12 patients receiving HD who had mean iPTH levels $>300 \mathrm{pg} / \mathrm{ml}$ despite 1 year of pulse IV calcitriol treatment. iPTH values were significantly lower after 1 year of pari-

Recognizing and Defining Vitamin D

Failure calcitol treatment (11 of 12 patients achieved iPTH levels $<300 \mathrm{pg} / \mathrm{ml}$ within 1 month of treatment initiation); calcium levels were slightly but significantly higher; phosphorus values were slightly but significantly lower; and calcium $\times$ phosphorus product did not change. In a study of 37 patients with iPTH levels $\geq 600 \mathrm{pg} / \mathrm{ml}$ despite treatment with calcitriol, a mean (SD) decrease in iPTH levels from 901 (58) pg/ml at baseline to 165 (24) pg/ml after 16 months of treatment with paricalcitol was noted. Serum calcium and phosphorus levels did not change during the study [45]. A retrospective analysis in $73 \mathrm{HD}$ patients evaluated the effects of switching from $\geq 6$ months of treatment with calcitriol to 6 months of treatment with paricalcitol. At 6 months, iPTH levels were significantly lower $(p=0.03)$, as were calcium levels $(p=0.05)$ and the calcium $\times$ phosphorus product $(\mathrm{p}=0.01)$ [51]. Vulpio et al. [47] conducted a switch study (described earlier) in 30 HD patients with iPTH levels $>300 \mathrm{pg} / \mathrm{ml}$, calcium levels from 8.0 to $10.5 \mathrm{mg} / \mathrm{dl}$, and calcium $\times$ phosphorus product $<70 \mathrm{mg}^{2} / \mathrm{dl}^{2}\left(5.6 \mathrm{mmol}^{2} / \mathrm{l}^{2}\right)$ after $\geq 6$ months of treatment with calcitriol. Patients were divided into 2 groups, depending on the MLD of the largest parathyroid gland ( $\leq 9$ vs. $>9 \mathrm{~mm}$ ). In patients with an MLD of $\leq 9 \mathrm{~mm}$, a significantly higher percentage achieved iPTH levels $<300 \mathrm{pg} / \mathrm{ml}$ after 6 and 12 months of treatment with paricalcitol than with treatment with calcitriol $(\mathrm{p}=0.09)$. iPTH levels did not decrease significantly in patients with an MLD of $>9 \mathrm{~mm}$.

These 'switch' studies provide preliminary evidence that paricalcitol may be a viable option for active vitamin $\mathrm{D}$ failure; however, they do not imply that paricalcitol is superior to calcitriol. Indeed, these results may reflect the fact that some patients may respond better to 1 active vitamin $\mathrm{D}$ treatment than another, even though they belong to the same class of agents. It is important to assess the various agents available before confirming that active vitamin $\mathrm{D}$ treatment has failed in a patient. Furthermore, confirmation is needed because of the inherent variability in test results, as was observed when $41.9 \%$ of patients achieved success (i.e. iPTH $<300 \mathrm{pg} / \mathrm{ml}$ ) with calcitriol re-treatment after an earlier failure of the same therapy [48].

KDIGO guidelines recommend the use of calcimimetics alone or in combination with vitamin $\mathrm{D}$ treatment for patients with CKD stage 5 and elevated PTH [10]. Large clinical trials have demonstrated that in dialysis patients with SHPT, calcimimetics alone or in combination with vitamin D treatment substantially lowered levels of PTH, calcium, and phosphorous [52-54]. One randomized controlled trial to date has examined the use of calcimi- 
metics in nondialysis patients with CKD and SHPT [55]. Starting from a baseline mean iPTH level of $263.7,74 \%$ of all patients and $70 \%$ of patients not receiving vitamin $D$ treatment achieved a $\geq 30 \%$ decrease in iPTH. Serum calcium levels were also decreased; however, serum phosphorous increased $\geq 20 \%$ during the study. Therefore, the use of calcimimetics is currently not recommended for nondialysis patients with CKD stages 3-5, and further evaluation is needed [10].

\section{Conclusions}

SHPT in patients with severely compromised renal function is associated with profound negative consequences that may be alleviated with active vitamin $\mathrm{D}$ treatment. However, active vitamin D treatment is unsuccessful in some patients due to intolerance (hypercalcemia) or resistance (high PTH levels despite continued treatment). Here, we have provided a construct that incorporates the issues of treatment intolerance and resistance into one definition, that is, the construct of active vitamin D treatment failure (iPTH $>600 \mathrm{pg} / \mathrm{ml}$ after 6 months of IV active vitamin D treatment and corrected total calcium serum levels $>10.2 \mathrm{mg} / \mathrm{dl}$ ). We hope that this proposed definition will encourage further research and provide a useful framework for recognizing and addressing this important problem in clinical practice.

\section{Acknowledgments}

Editorial and medical writing support was provided by Mariana Ovnic and Roderick Sayce of Complete Publication Solutions, LLC; this support was funded by AbbVie Inc.

\section{Disclosure Statement}

This work was supported by AbbVie Inc. AbbVie Inc. funded and participated in the literature and database searches; the analysis and interpretation of data; and the drafting of the manuscript. All authors participated in drafting, critically reviewing, and approving the final manuscript for submission. M. Cozzolino has received honoraria for speaking and for performing advisory tasks from AbbVie Inc., Amgen Inc., Genzyme Corp., Shire Pharmaceuticals, Hoffmann-La Roche Inc., Vifor Pharma Ltd., and has received funding from AbbVie Inc., Takeda Pharmaceuticals USA, Inc., and Shire Pharmaceuticals. A. Covic has received honoraria for speaking and for performing advisory tasks from AbbVie Inc., Amgen Inc., Hoffmann-La Roche Inc., Vifor Pharma Ltd., and Fresenius Medical Care Holdings, Inc. B. Martinez-Placencia and K. Xynos are employees of AbbVie Inc., and may own AbbVie stock or stock options.

\section{References}

1 Centers for Disease Control and Prevention (CDC): National chronic kidney disease fact sheet: general information and national estimates on chronic kidney disease in the United States, 2014. US Department of Health and Human Services: Centers for Disease Control and Prevention. http://www.cdc.gov/diabe tes/pubs/pdf/kidney_factsheet.pdf (accessed March 12, 2015).

2 Jha V, Garcia-Garcia G, Iseki K, Li Z, Naicker S, Plattner B, Saran R, Wang AY, Yang CW: Chronic kidney disease: global dimension and perspectives. Lancet 2013;382:260272.

3 Dusso AS: Vitamin D receptor: mechanisms for vitamin D resistance in renal failure. Kidney Int Suppl 2003;85:S6-S9.

4 National Kidney Foundation: K/DOQI Clinical Practice Guidelines for Bone Metabolism and Disease in Chronic Kidney Disease. Am J Kidney Dis 2003;42(4 suppl 3):S1-S201.

5 Levin A, Bakris GL, Molitch M, Smulders M, Tian J, Williams LA, Andress DL: Prevalence of abnormal serum vitamin $\mathrm{D}, \mathrm{PTH}$, calcium, and phosphorus in patients with chronic kidney disease: results of the study to evaluate early kidney disease. Kidney Int 2007;71:3138.
6 Cunningham J, Locatelli F, Rodriguez M: Secondary hyperparathyroidism: pathogenesis, disease progression, and therapeutic options. Clin J Am Soc Nephrol 2011;6:913-921.

7 Goodman WG, Goldin J, Kuizon BD, Yoon C, Gales B, Sider D, Wang Y, Chung J, Emerick A, Greaser L, Elashoff RM, Salusky IB: Coronary-artery calcification in young adults with end-stage renal disease who are undergoing dialysis. N Engl J Med 2000;342:14781483.

8 Blacher J, Guerin AP, Pannier B, Marchais SJ, London GM: Arterial calcifications, arterial stiffness, and cardiovascular risk in end-stage renal disease. Hypertension 2001;38:938-942.

9 Brancaccio D, Cozzolino M, Cannella G, Messa P, Bonomini M, Cancarini G, Caruso MR, Cascone C, Costanzo AM, di Luzio Paparatti U, Mazzaferro S; FARO Study Group: Secondary hyperparathyroidism in chronic dialysis patients: results of the Italian FARO survey on treatment and mortality. Blood $\mathrm{Pu}$ rif 2011;32:124-132.

10 Kidney Disease: Improving Global Outcomes (KDIGO) CKD-MBD Work Group: KDIGO clinical practice guideline for the diagnosis, evaluation, prevention, and treatment of chronic kidney disease-mineral and bone dis- order (CKD-MBD). Kidney Int Suppl 2009; 113:S1-S130.

11 Andress DL: Vitamin D in chronic kidney disease: a systemic role for selective vitamin $D$ receptor activation. Kidney Int 2006;69:3343.

12 Renkema KY, Alexander RT, Bindels RJ, Hoenderop JG: Calcium and phosphate homeostasis: concerted interplay of new regulators. Ann Med 2008;40:82-91.

13 Rodriguez M, Nemeth E, Martin D: The calcium-sensing receptor: a key factor in the pathogenesis of secondary hyperparathyroidism. Am J Physiol Renal Physiol 2005; 288:F253-F264.

14 Cozzolino M, Galassi A, Apetrii M, Covic A: What would we like to know, and what do we not know about fibroblast growth factor 23? J Nephrol 2011;24:696-706.

15 Komaba H, Fukagawa M: FGF23-parathyroid interaction: implications in chronic kidney disease. Kidney Int 2010;77:292-298.

16 Fukuda N, Tanaka H, Tominaga Y, Fukagawa M, Kurokawa K, Seino Y: Decreased 1,25-dihydroxyvitamin D3 receptor density is associated with a more severe form of parathyroid hyperplasia in chronic uremic patients. J Clin Invest 1993;92:1436-1443. 
17 Gogusev J, Duchambon P, Hory B, Giovannini M, Goureau Y, Sarfati E, Drüeke TB: Depressed expression of calcium receptor in parathyroid gland tissue of patients with hyperparathyroidism. Kidney Int 1997;51:328336.

18 Komaba H, Goto S, Fujii H, Hamada Y, Kobayashi A, Shibuya K, Tominaga Y, Otsuki N, Nibu K, Nakagawa K, Tsugawa N, Okano T, Kitazawa R, Fukagawa M, Kita T: Depressed expression of Klotho and FGF receptor 1 in hyperplastic parathyroid glands from uremic patients. Kidney Int 2010;77:232-238.

19 Yano S, Sugimoto T, Tsukamoto T, Chihara K, Kobayashi A, Kitazawa S, Maeda S, Kitazawa R: Association of decreased calcium-sensing receptor expression with proliferation of parathyroid cells in secondary hyperparathyroidism. Kidney Int 2000;58:1980-1986.

20 Dawson-Hughes B, Harris SS, Ceglia L, Palermo NJ: Effect of supplemental vitamin D and calcium on serum sclerostin levels. Eur J Endocrinol 2014;170:645-650.

21 Ryan ZC, Ketha H, McNulty MS, McGeeLawrence M, Craig TA, Grande JP, Westendorf JJ, Singh RJ, Kumar R: Sclerostin alters serum vitamin $\mathrm{D}$ metabolite and fibroblast growth factor 23 concentrations and the urinary excretion of calcium. Proc Natl Acad Sci U S A 2013;110:6199-6204.

22 Sprague SM, Silva AL, Al-Saghir F, Damle R, Tabash SP, Petkovich M, Messner EJ, White JA, Melnick JZ, Bishop CW: Modified-release calcifediol effectively controls secondary hyperparathyroidism associated with vitamin $\mathrm{D}$ insufficiency in chronic kidney disease. Am J Nephrol 2014;40:535-545.

23 Chandra P, Binongo JN, Ziegler TR, Schlanger LE, Wang W, Someren JT, Tangpricha $\mathrm{V}$ : Cholecalciferol (vitamin D3) therapy and vitamin $\mathrm{D}$ insufficiency in patients with chronic kidney disease: a randomized controlled pilot study. Endocr Pract 2008;14:1017.

24 Moe SM, Saifullah A, LaClair RE, Usman SA, Yu Z: A randomized trial of cholecalciferol versus doxercalciferol for lowering parathyroid hormone in chronic kidney disease. Clin J Am Soc Nephrol 2010;5:299-306.

25 Zisman AL, Hristova M, Ho LT, Sprague SM: Impact of ergocalciferol treatment of vitamin $D$ deficiency on serum parathyroid hormone concentrations in chronic kidney disease. Am J Nephrol 2007;27:36-43.

26 Cozzolino M, Ketteler M, Martin KJ, Sharma A, Goldsmith D, Khan S: Paricalcitol- or cinacalcet-centred therapy affects markers of bone mineral disease in patients with secondary hyperparathyroidism receiving haemodialysis: results of the IMPACT-SHPT study. Nephrol Dial Transplant 2014;29: 899-905.

27 Biggar P, Kovarik J, Klauser-Braun R, Graf H, Müller HW, Veres A, Seidinger S, Ketteler M: Paricalcitol treatment of secondary hyperparathyroidism in hemodialysis patients: a German-Austrian, single-arm, open-label, prospective, noninterventional, observational study. Nephron Clin Pract 2014;126:39-50.

28 Teng M, Wolf M, Ofsthun MN, Lazarus JM, Hernán MA, Camargo CA Jr, Thadhani R: Activated injectable vitamin $\mathrm{D}$ and hemodialysis survival: a historical cohort study. J Am Soc Nephrol 2005;16:1115-1125.

29 Tentori F, Hunt WC, Stidley CA, Rohrscheib MR, Bedrick EJ, Meyer KB, Johnson HK, Zager PG: Mortality risk among hemodialysis patients receiving different vitamin $\mathrm{D}$ analogs. Kidney Int 2006;70:1858-1865.

30 Kovesdy CP, Ahmadzadeh S, Anderson JE, Kalantar-Zadeh K: Association of activated vitamin $\mathrm{D}$ treatment and mortality in chronic kidney disease. Arch Intern Med 2008;168: 397-403.

31 Shoben AB, Rudser KD, de Boer IH, Young B, Kestenbaum B: Association of oral calcitriol with improved survival in nondialyzed CKD. J Am Soc Nephrol 2008; 19:1613-1619.

32 Duranton F, Rodriguez-Ortiz ME, Duny Y, Rodriguez M, Daurès JP, Argilés A: Vitamin $\mathrm{D}$ treatment and mortality in chronic kidney disease: a systematic review and meta-analysis. Am J Nephrol 2013;37:239-248.

33 Cozzolino M, Brancaccio D, Cannella G, Messa $P$, Gesualdo L, Marangella M, LoDeserto C, Pozzato M, Rombolà G, Costanzo AM, di Luzio Paparatti U, Mazzaferro S; FARO Study Group: VDRA therapy is associated with improved survival in dialysis patients with serum intact PTH $\leq 150 \mathrm{pg} / \mathrm{ml}$ : results of the Italian FARO survey. Nephrol Dial Transplant 2012; 27:3588-3594.

34 Goldsmith DJ, Covic A, Fouque D, Locatelli F, Olgaard K, Rodriguez M, Spasovski G, Urena P, Zoccali C, London GM, Vanholder R: Endorsement of the Kidney Disease Improving Global Outcomes (KDIGO) Chronic Kidney Disease-Mineral and Bone Disorder (CKD-MBD) Guidelines: a European Renal Best Practice (ERBP) commentary statement. Nephrol Dial Transplant 2010;25:3823-3831.

35 Al Rukhaimi M, Al Sahow A, Boobes Y, Goldsmith D, Khabouth J, El Baz T, Mahmoud H, Ganji MR, Shaheen FA: Adaptation and implementation of the 'Kidney Disease: Improving Global Outcomes (KDIGO)' guidelines for evaluation and management of mineral and bone disorders in chronic kidney disease for practice in the Middle East countries. Saudi J Kidney Dis Transpl 2014;25:133-148.

36 Uhlig K, Berns JS, Kestenbaum B, Kumar R, Leonard MB, Martin KJ, Sprague SM, Goldfarb S: KDOQI US commentary on the 2009 KDIGO Clinical Practice Guideline for the Diagnosis, Evaluation, and Treatment of CKD-Mineral and Bone Disorder (CKDMBD). Am J Kidney Dis 2010;55:773-799.

37 Sprague SM, Llach F, Amdahl M, Taccetta C, Batlle D: Paricalcitol versus calcitriol in the treatment of secondary hyperparathyroidism. Kidney Int 2003;63:1483-1490.

38 Thadhani R, Appelbaum E, Pritchett Y, Chang Y, Wenger J, Tamez H, Bhan I, Agarwal R, Zoccali C, Wanner C, Lloyd-Jones D,
Cannata J, Thompson BT, Andress D, Zhang W, Packham D, Singh B, Zehnder D, Shah A, Pachika A, Manning WJ, Solomon SD: Vitamin D therapy and cardiac structure and function in patients with chronic kidney disease: the PRIMO randomized controlled trial. JAMA 2012;307:674-684.

39 Brown AJ, Ritter CR, Finch JL, Morrissey J, Martin KJ, Murayama E, Nishii Y, Slatopolsky $\mathrm{E}$ : The noncalcemic analogue of vitamin $\mathrm{D}$, 22-oxacalcitriol, suppresses parathyroid hormone synthesis and secretion. J Clin Invest 1989;84:728-732.

40 Brown AJ, Dusso A, Slatopolsky E: Vitamin D. Am J Physiol 1999;277(2 pt 2):F157-F175.

41 Hansen D, Rasmussen K, Danielsen H, Meyer-Hofmann H, Bacevicius E, Lauridsen TG, Madsen JK, Tougaard BG, Marckmann P, Thye-Roenn P, Nielsen JE, Kreiner S, Brandi L: No difference between alfacalcidol and paricalcitol in the treatment of secondary hyperparathyroidism in hemodialysis patients: a randomized crossover trial. Kidney Int 2011; 80:841-850.

42 Coyne DW, Goldberg S, Faber M, Ghossein C, Sprague SM: A randomized multicenter trial of paricalcitol versus calcitriol for secondary hyperparathyroidism in stages $3-4$ CKD. Clin J Am Soc Nephrol 2014;9:16201626.

43 Jamaluddin EJ, Gafor AH, Yean LC, Cader R, Mohd R, Kong NC, Shah SA: Oral paricalcitol versus oral calcitriol in continuous ambulatory peritoneal dialysis patients with secondary hyperparathyroidism. Clin Exp Nephrol 2014;18:507-514.

44 Negri AL, Brandemburg VM: Calcitriol resistance in hemodialysis patients with secondary hyperparathyroidism. Int Urol Nephrol 2014; 46:1145-1151.

45 Llach F, Yudd M: Paricalcitol in dialysis patients with calcitriol-resistant secondary hyperparathyroidism. Am J Kidney Dis 2001; 38(5 suppl 5):S45-S50.

46 Tonbul HZ, Solak Y, Atalay H, Turkmen K, Altintepe L: Efficacy and tolerability of intravenous paricalcitol in calcitriol-resistant hemodialysis patients with secondary hyperparathyroidism: 12-month prospective study. Ren Fail 2012;34:297-303.

47 Vulpio C, Maresca G, Distasio E, Cacaci S, Panocchia N, Luciani G, Bossola M: Switch from calcitriol to paricalcitol in secondary hyperparathyroidism of hemodialysis patients: responsiveness is related to parathyroid gland size. Hemodial Int 2011;15:69-78.

48 Kazama JJ, Sato F, Omori K, Hama H, Yamamoto S, Maruyama H, Narita I, Gejyo F, Yamashita T, Fukumoto S, Fukagawa M: Pretreatment serum FGF-23 levels predict the efficacy of calcitriol therapy in dialysis patients. Kidney Int 2005;67:1120-1125.

49 Capuano A, Serio V, Pota A, Memoli B, Andreucci VE: Beneficial effects of better control of secondary hyperparathyroidism with paricalcitol in chronic dialysis patients. J Nephrol 2009;22:59-68. 
50 Rodriguez M, Caravaca F, Fernandez E, Borrego MJ, Lorenzo V, Cubero J, Martin-Malo A, Betriu A, Jimenez A, Torres A, Felsenfeld AJ: Parathyroid function as a determinant of the response to calcitriol treatment in the hemodialysis patient. Kidney Int 1999;56:306-317.

51 Mittman N, Khanna R, Rani S, Chattopadhyay J, Avram MM: Paricalcitol therapy for secondary hyperparathyroidism in patients on maintenance hemodialysis previously treated with calcitriol: a single-center crossover study. Kidney Int 2006;70:S64-S67.

52 Block GA, Martin KJ, de Francisco AL, Turner SA, Avram MM, Suranyi MG, Hercz G, Cunningham J, Abu-Alfa AK, Messa P, Coyne
DW, Locatelli F, Cohen RM, Evenepoel P, Moe SM, Fournier A, Braun J, McCary LC, Zani VJ, Olson KA, Drüeke TB, Goodman WG: Cinacalcet for secondary hyperparathyroidism in patients receiving hemodialysis. $\mathrm{N}$ Engl J Med 2004;350:1516-1525.

53 Lindberg JS, Culleton B, Wong G, Borah MF, Clark RV, Shapiro WB, Roger SD, Husserl FE, Klassen PS, Guo MD, Albizem MB, Coburn JW: Cinacalcet $\mathrm{HCl}$, an oral calcimimetic agent for the treatment of secondary hyperparathyroidism in hemodialysis and peritoneal dialysis: a randomized, double-blind, multicenter study. J Am Soc Nephrol 2005;16: 800-807.
54 Block GA, Zeig S, Sugihara J, Chertow GM, Chi EM, Turner SA, Bushinsky DA; TARGET Investigators: Combined therapy with cinacalcet and low doses of vitamin D sterols in patients with moderate to severe secondary hyperparathyroidism. Nephrol Dial Transplant 2008;23:2311-2318.

55 Chonchol M, Locatelli F, Abboud HE, Chary$\tan$ C, de Francisco AL, Jolly S, Kaplan M, Roger SD, Sarkar S, Albizem MB, Mix TC, Kubo Y, Block GA: A randomized, doubleblind, placebo-controlled study to assess the efficacy and safety of cinacalcet $\mathrm{HCl}$ in participants with CKD not receiving dialysis. Am J Kidney Dis 2009;53:197-207. 